and England and Scotland) and resulted in the first cases of kala azar in British soldiers, reported in the Middle East Force in World War II, being diagnosed in 53 General Hospital in Eritrea; the disease having been acquired in the Gederef-Gallabat area of the Sudan (Mackay-Dick 1945). Connolly and Thomas (1970) do well to re-emphasise the importance of an accurate geographical history.

\title{
REFERENCES
}

Connolly, T. P. \& Thomas, M. J. C. (1970). J. roy. Army med. Cps. 116, 54.

MACKAY-Dick, J. (1945). J. roy. Army med. Cps. 85, 68.

I am, etc.,

\section{John MACKAY-DICK}

80 Ravelston Dykes,

Edinburgh, EH12. 6HE.

12 February 1970.

\section{BOOK REVIEWS}

Shoulder Lesions. Third Edition. H. F. Moseley. Edinburgh. E. \& S. Livingstone Ltd. 1969. Pp. xv + 318. 240s. Illustrated.

This work by a recognised authority on the shoulder region can only be classified as admirable.

Using anatomical bases initially, it gives clear expositions of the varying lesions together with their treatments, both conservative and operative.

Chapters on radiology and rehabilitation are included and a further one on the neurological aspects of shoulder lesions.

The excellent contents deserve and reosive an equally good presentation. The print is clear and the quality of the illustrations good.

The book must be recommended to all who deal with shoulder lesions and, it should be in every hospital library.

G. I. SMALL

Montgomery The Field Marshal. The Campaign in North-West Europe 1944-5. R. W. THOMPSON. Hemel Hempstead. George Allen \& Unwin Ltd. 1969. P.344. 50s.

This book deals with the campaign in N.W. Europe 1944-5 and in particular with the Generalship of Montgomery. The author writes with authority, clarity, understanding and objectivity and has produced the best account of this campaign which I have read.

Mr. Thompson is eminently fair and writes with sympathy and understanding of the forces and stresses which arose and which made Eisenhower's team such a difficult one to control. Unlike some writers he does recognise that the Americans had very good reasons (from their point of view) for their actions and opinions and he sets these out clearly and fairly. The result of this admirable objectivity is that the author captures the reader's confidence and respect, and this gives his study its authority.

I have no intention of spoiling this book for the reader by summarising it-all I need say is that Montgomery's Generalship is carefully analysed and his failures as well as his successes noted.

It was pleasant to read the author's tribute to General Dempsey who has not received the recognition which he so well earned in N. W. Europe.

My only criticism is that the maps and the production of the book are poor and unworthy of Mr. Thompson's text and the relatively high price asked.

In short I find it hard to over-praise this book which is in a class by itself. It can be most strongly recommended to any reader who wishes for a clear, objective and impartial account of the Campaign in N.W. Europe 1944-5.

A. MacLenNan

Tumours of the Urinary Bladder. K. P. SARMA. London. Butterworth \& Co. Ltd. 1969. Pp. xii +431.100 s.

Mr. Sarma has written an encyclopedic account of bladder tumours. He starts with a basic study of the bladder and proceeds to consider every aspect of its tumours in detail. Operative procedures are described in detail.

This is an excellent reference book and has a very full bibliography.

I. M. Cran

Livingstone Books 1970

A complete catalogue of Livingstone Books for 1970 is available, free of charge, on request to E. \& S. Livingstone Ltd., Teviot Place, Edinburgh. 
Surgeons in the Field. J. LAFFIN. London. J. M. Dent \& Sons Ltd. 1970. P. 296. 50s. Illustrated.

Over the past few years the author has produced some sixteen or so books on a diversity of military subjects. All are written for the general reader and in consequence are more popular presentations than professional studies.

Mr. Laffin's latest book-"Surgeons in the Field"-follows the same pattern and is a presentation, intended for the general reader, of the medical care of the soldier in war from the earliest period to World War II. It fills a long felt gap as no such account for the general reader was available previously.

The author starts off well and his early chapters are admirable, thereafter he tends to skip about with a consequent lack of continuity in his story; in addition the individual chapters vary in quality so that the impression is of a book written against the clock rather than of a well considered and mature study.

Unhappily Chapter 18-" Development of the British Army Medical Service " which in particular will be turned to by our Corps readers, highlights the shortcomings of the book. The chapter begins well (being based very largely on Peter Lovegrove's " Not least in the Crusade ") but then tails off into a disjointed catalogue of achievements which read more like the headings in the author's working notebook than as a deliberate piece of writing. Finally in the middle of this catalogue without any lead in appears a diagram and notes of a Casualty Evacuation System by that celebrated Corps historian-Evatt -in 1885. The consequence is that unless the reader is a specialist in our Corps history he is left wondering if the diagram represents an ideal system evolved in Evatt's imagination or an organisation which actually existed in 1885 .

The author's footnotes require to be treated with caution. Three examples will illustrate this. Firstly on page 98 a footnote informs us that James Barry's "sex was officially discovered after her death in 1865." It was the charwoman who laid out Barry's body for burial who started the rumours that the body was that of a female. The death certificate-which was never altered-described Barry as a male and was made out by Surgeon Major McKinnon. The verdict still remains the Scottish one of "Not proven". Secondly on page 165 a footnote states that the Prussian needle-gun was in use in Prussia in 1842 and that when the trigger was pressed the firing needle passed through the primer (of the cartridge) and hit the powder ahead. Both these statements are inaccurate. The first Dreyse Needle Gun to be issued to the Prussian Army was the M 41 (Model 1841). The date refers to the start of manufacture and not to the date of issue. The first issues of the M 41 to Prussian troops began in 1848. The needle, when the trigger was pressed, pierced the base of the paper cartridge, passed through the black powder charge and not till then struck the primer or detonating patch which was on the base of a cardboard wad of cup shape in which the bullet rested. Thirdly, on page 207 a footnote informs us that Martin-Leake gained a second V.C. in 1914 and later died of wounds. He in fact survived for almost another 40 years dying in 1953.

Most readers will find the frequent absence of Capital letters in the tables irritating besides making them difficult to read.

One of the best features of the book are the illustrations which are excellent and among which our readers will greet many old acquaintances.

In the list of Acknowledgements it is gratifying to note that that Corps stalwart-the late Major General Eric Barnsley-has been promoted to Director General!

It is also noted that an old friend-Mr. Tompkinson of the Photographic Department R.A.M. College-is hiding his (flash) light under the guise of Tomlinson!

To sum up then this is a well produced, printed and illustrated book which should prove to be interesting and instructive to the general reader.

Our Corps readers, for whom this review is written, will be more critical and will regret the author's failure to spend more time and to take greater care in writing his book. Not only has he failed to produce a first class work but he has neither done justice to his ability to write clear and vigorous prose nor to his obvious mastery of his subject. Festina lente!

A. MacLennan

The Medical Services of the United States Army in World War $\mathbf{I}$. Editor-in-Chief, Colonel $\mathbf{R}$. S. ANDERson. Editor for Medical Supply, C. W. WILTSE. Washington D.C. Office of the Surgeon General, United States Army. 1968. Pp. xxv + 662. \$8.25. Illustrated.

This magnificently illustrated history, enhanced with excellent photographs and maps, traces the American Army medical supply organisation through its initial formative period when it was concerned mainly with Lend-Lease; through its period of maximum activity during the war, and during redevelopment and "run-down" operations which eventually led to a static peace time structure in support of occupation forces.

It is a story of frequent frustration and initial confusion and then, in due course of outstanding success. It describes activities in the various aspects of medical supply in many parts of the world; with those concerning Europe and Great Britain being of special interest to readers in this country.

It is intriguing to read that in the early days of Lend-Lease one recipient (who shall be nameless) requested medical supplies for 50 infantry and 20 cavalry divisions, this ambitious requirement being disapproved when it was found that the entire army of the country concerned amounted to only 5 divisions.

Reading the accounts of the problems overcome, wherever American troops were stationed throughout the world, leaves one breathless and with a sincere feeling of admiration and respect for the U.S. Army Medical supply system. 
This is a book which, even today, has lessons for all those concerned with the supply and maintenance of medical and dental equipment to the fighting Services.

Alan KeatingB

Henderson and Gillespie's Textbook of Psychiatry. Tenth Edition. Revised by I. R. C. BATCHELOR. London. Oxford University Press. 1969. Pp. xii +578 . Bds. 60s. Paper 42s.

This standard textbook was very extensively revised in its ninth edition in 1962. The tenth edition successfully incorporates established new material over the past seven years and contains a new chapter on dependance on drugs and alcohol. This is an admirably concise account of current views on a rapidly increasing problem. The chapter on occupational therapy has been expanded to include the wider aspects of re-habilitation. Of particular interest in this chapter are fair and balanced, if somewhat critical, reviews of the Therapeutic Community and of the Day Hospital. Since the last edition the more obscure features of the Mental Health Act (1959) have been legally tested. This has enabled the revisor to replace the previous chapter under the new heading of Forensic Psychiatry, with a clear statement of the Law on psychiatric hospital admission. The section on reports to the court is a valuable guide and will be particularly useful to Service psychiatrists who are increasingly called upon to make such statements to civil courts.

With the inclusion of so much new material it is a considerable achievement to have avoided any increase in size in the new edition. Certain statements, for example that "it is doubtful if alcoholic hallucinosis is a clinical entity ", would not be accepted by many authorities. However some such didactic statements are probably inevitable if the text is not to be expanded.

This textbook will maintain its place for the under-graduate and recent post-graduate student. For the latter it will remain the standard basic work on descriptive psychiatry for Part Two of the D.P.M., and the earlier sections for those aspects of symptomatology and aetiology required in Part One.

R. A. Dunbar Miller

Head Injured Men. Fifteen Years Later. A. EARL WALKER and F. ERculeI. Illinois. Charles C. Thomas. 1968. Pp vii + 118. \$7.50.

This continuing review of over 300 men who sustained open head injuries in World War II is providing valuable data. As they have been studied on two occasions previously, a good analysis of the progression, or natural history of the injury can be made. It may come as a surprise to most readers that, in general, these men have not become worse with age.

This is a valuable reference book.

I. M. CRAN

Renin and Hypertension. A Moderm Synthesis. M. R. LeE. London. Lloyd-Luke (Medical Books) Ltd. 1969. Pp. viii + 224. 45s. Mllustrated.

The renin-angiotensin system has attracted considerable interest in recent years both in the experimental and clinical fields. The literature is large and at time confusing and conflicting. Dr. Lee has produced a concise, scholarly account which reflects his enthusiasm for the subject. The emphasis is largely on the laboratory aspects but the book ends on a clinical note with a discussion on renal hypertension, adrenal disorders, pregnancy and some rare syndromes including the renin producing haemangiopericytoma of the kidney.

The limited-availability of assay methods for renin, angiotensin and aldosterone restricts the practical use to which a military physician can put this book but nonetheless it may be read with great profit.

I. C. CRAWFord.

Operative Surgery Revision. Second Edition. J. J. ShIPMAN. London. H. K. Lewis \& Co. Ltd. 1969. Pp. vii $+171.35 \mathrm{~s}$.

Those who are well prepared for the Final FRCS examination will find this book valuable for quick revision. Those who are unprepared will find it alarming; they will soon realise what they should have learnt and how their knowledge should have been arranged.

Most surgeons like to make their own list of essential steps for various operations, but all will benefit from the stimulus of reading this book. Wherever surgeons are working for the Fellowship this book should be in the library.

I. M. CRAN

Care of the Newly Born Infant. Fourth Edition. W. S. CRAIG. Edinburgh. E. \& S. Livingstone Ltd. 1969. Pp. xiii +749 . 65 s. Illustrated.

This is the fourth edition of this deservedly popular text book first published in 1956. It has been updated by a number of changes in certain chapters and the addition of several new chapters. The original format and method of presentation have wisely been retained and we have, as a result, a book which is pleasant and easy to read.

The black and white illustrations are numerous and good but it was felt that those in colour added lit tle of value.

Although the subject of the book of necessity renders it of more importance to the midwife or trained nurse, nevertheless, there is much of interest for the general practitioner, obstetrician and paediatrician. Its approach is essentially practical and largely non-controversial in context.

This is a book which should be in the library or on the bookshelf of all those who undertake the care of the newborn baby.

R. G. EMERSON 